\title{
Indoor Tanning, Sunbathing, and the Hazard of Skin Cancer: The Effect of the Tan Tax
}

\author{
Gideon Yaniv*, Erez Siniver \\ School of Economics, COMAS, Rishon LeZion, Israel \\ Email: "gidyan@colman.ac.il
}

Received 9 January 2015; accepted 29 January 2015; published 30 January 2015

Copyright (C) 2015 by authors and Scientific Research Publishing Inc.

This work is licensed under the Creative Commons Attribution International License (CC BY).

http://creativecommons.org/licenses/by/4.0/

(c) (i) Open Access

\begin{abstract}
In July 2010, a 10 percent federal sales tax on indoor tanning, known as the tan tax, went into effect. Applauding the imposition of the new tax, the American Academy of Dermatology (AAD) foresees that by discouraging indoor tanning, the tan tax will significantly reduce the risk of skin cancer and consequently the future costs of its treatment, currently amounting to \$1.8 billion each year. Recognizing, however, that an alternative to indoor tanning may be the riskier practice of sunbathing, the present paper offers a rational-choice model for addressing the individual's indoor and outdoor tanning decisions, which is applied to examining his or her response to the imposition of a tan tax and the consequent effect on the hazard of developing skin cancer. The paper challenges the AAD's forecast, identifying conditions under which a tan tax will rather exacerbate the hazard of skin cancer.
\end{abstract}

Keywords

Indoor Tanning, Sunbathing, Skin Cancer, Tan Tax

\section{Introduction}

While generations ago tanned skin was associated with lower status, specifically with peasants having to work outside under the hot sun, now a suntan has become a status symbol, not only making one look healthier, more active and attractive, but also projecting to the world that he or she is successful and having enough free time to sun bathe and enjoy the good life. Unfortunately, this sun-kissed look, which seems to be the symbol of glowing health, is in actual fact the opposite: sunlight consists of ultraviolet radiation, which is the primary cause of premature skin aging and all forms of skin cancer ${ }^{1}$. As reported by the National Cancer Institute [2], ninety per-

\section{${ }^{*}$ Corresponding author.}

${ }^{1}$ While responsible for the production of tan, ultraviolet radiation damages the skin's cellular DNA, promotes the formation of free-radicals in the cell, causes the breakdown of collagen and inhibits the workings of the immune system. Eventually, it causes the skin to prematurely age with wrinkles, altered pigmentation and reduced elasticity, and might produce genetic mutations that lead to flesh-colored skin cancers and malignant melanomas [1]. 
cent of all skin cancers are thought to be caused by ultraviolet radiation. The incidence of skin cancer in the USA has been increasing several percent annually for the past four decades, becoming the most common form of cancer and accounting for half of all human malignancies [3].

An alternative to getting a tan by exposure to sunlight is tanning indoor by exposing oneself to an artificial source of intermittent ultraviolet radiation, such as a tanning bed or booth in a tanning salon. Indoor tanning has gained popularity in the USA since the early 1980s, with approximately 30 million Americans currently visiting tanning salons each year $[4]^{2}$. A recent report based on data collected from 116 cities in the USA found that the average number of tanning salons exceeded the average number of Starbucks or McDonald's [8]. While the indoor tanning industry claims to offer an effective, quick and harmless alternative to natural sunlight, there is growing evidence that the ultraviolet radiation emitted by tanning lamps is far from being safe [9]. As a result, and in view of the size of the tanning industry in terms of commercial tanning facilities and the number of people using them, indoor tanning has become a major public health issue.

On July 1st 2010, a 10 percent federal sales tax on indoor tanning services, known as the tan tax, went into effect $^{3}$. While the new tax was intended to help fund the health care bill, rather than to act as a deterrent to indoor tanning, it was applauded by the American Academy of Dermatology (AAD), which announced that the tan tax sent a clear message to the public, young women in particular, that indoor tanning was a dangerous activity that should be avoided [10]. By discouraging indoor tanning, the AAD foresees that the tan tax will significantly reduce the risk of skin cancer and consequently the future costs of its treatment, currently amounting to $\$ 1.8$ billion each year [11]. However, in a technical letter to the editor of a medical journal, seven years before the imposition of the tan tax, Sayre and Dowdy [12] set forth a relative risk argument that sheds doubt on the AAD's forecast:

"It is important to remember that the risk associated with any activity is best considered relative to the risk of the probable alternative behavior. For tanners, the alternative to the controlled, scheduled exposures received in a tanning unit is the more hazardous uncontrolled practice of outdoor sunbathing" (p. 107).

Sayre and Dowdy's argument should not come as a surprise to economists. It is well documented in the economic literature that people tend to adjust their behavior to public policies in ways that counteract the intended effects of the policies, offsetting some or all of their potential benefit. In a classic article, Peltzman [13] offered statistical evidence that the legally mandated installation of various safety devices on automobiles, which resulted in fewer deaths per accident, had no effect on highway fatalities, since drivers responded to it by driving more recklessly, thereby increasing the number of accidents. Similarly, Evans and Farrelly [14] found that smokers responded to higher cigarette taxes by smoking cigarettes with higher tar and nicotine content. In a widely reported study, Green [15] concluded that no consistent association existed among the distribution of condoms to countries in sub-Saharan Africa and lower HIV-infection rates, apparently because making sex safer reduced the incentive to avoid sex with risky partners. Yaniv et al. [16], applying a calorie-intake/calorie-use rational choice model to examine the possible effects on obesity of the widely discussed fat tax program, showed that a fat tax on junk food might end up increasing obesity, since by encouraging time-intensive preparation of healthy food it left less time for physical activity. Fletcher et al. [17] concluded that the moderate reduction in soft drink consumption in response to soft drink taxation, as currently practiced in the United States, was completely offset by increases in consumption of other high-calorie beverages. Finally, Just and Wansink [18] conducted an experiment in an all-you-can-eat pizza buffet to show that a customer would eat more in response to a higher entry price so as to get his or her money's worth. This implies that subjecting all-you-can-eat buffets to the fat tax program, while reducing the frequency of visiting buffets, may end up contributing to the weight of buffet patrons. However, Siniver and Yaniv [19], conducting an experiment in an all-you-can-eat sushi restaurant, showed that a fat tax would increase eating only if the buffet price was greater than the cost required to reach fullness under a-la-carte dining system.

\footnotetext{
${ }^{2}$ Women aged 20 - 39 years appear to be the most frequent users of tanning salons [5]. Approximately $40 \%-60 \%$ of college students have used indoor tanning booths, with higher rates among women [6]. Older adults also tan indoors: a national study of indoor tanning across adult age groups in the USA found rates of past year indoor tanning of $14.2 \%$ for 18 - 34 years old, $9.2 \%$ for 35 - 39 years old, $10.6 \%$ for 40 - 44 years old, and $3.9 \%$ for those 45 and older [7].

${ }^{3}$ The tan tax is part of the USA Patient Protection and Affordable Care Act, signed into law by President Barak Obama on March 23rd, 2010. Along with the Health Care and Education Reconciliation Act of 2010 it constitutes the principal health care reform legislation of the 111th USA congress. The 10 percent tax on indoor tanning services has replaced a 5 percent tax on cosmetic surgery that was originally included in the Act. That tax, nicknamed the "Botax", would have included Botox injections and breast implements among other elective surgeries, but was cut out of the Act after heavy lobbying from the medical and dermatology industries.
} 
The present paper formalizes Sayre and Dowdy's [12] relative risk argument, offering an economic-rationalchoice model for addressing the individual's indoor and outdoor tanning decision ${ }^{4}$. The model is then applied to examining his or her response to the introduction of a tan tax and the consequent effect on the hazard of developing skin cancer. While the idea that tanners may respond to the imposition of a tan tax by increasing their exposure to the sun is not surprising, whether the hazard of developing skin cancer decreases or increases as a result is not obvious, but depends on the extent by which the fall in indoor tanning is offset by a rise in sunbathing and by the relative hazardousness of the alternative tanning tracks: while a minute under the lamp is more hazardous than a minute under the sun, it takes more time to get tanned under the latter. Consequently, an outdoor tanning session may be more hazardous than an indoor session. The paper challenges the AAD's forecast, identifying conditions on the parameters of the model under which a tan tax would rather exacerbate the hazard of skin cancer. The extent by which sunbathing is perceived as a leisure-type activity rather than purely an input in the tan production process is shown to play a crucial role in determining the effect of the tan tax.

\section{The Model}

Consider an individual who derives pleasure from a tanned look. Suppose that tan can be produced either indoor, by exposure to an artificial source of ultraviolet radiation in a tanning booth, or outdoor, by bathing in the sun. More specifically, suppose that it takes a session of 1 unit of time to get tanned in a tanning booth and a session of $\theta$ units of time to get tanned in the sun, where $\theta>1^{5}$. While it takes more time to get tanned in the sun, suppose that sunlight is readily available in the individual's back yard, park or local beach, involving no monetary cost. Getting tanned in a tanning booth, however, costs $p$ dollars per session.

While tanning in a booth disables the individual from being engaged in anything else during the production process, tanning in the sun may be accompanied with a variety of leisure-type activities such as reading, swimming, fishing, or ball playing. Let $0 \leq \alpha \leq 1$ denote the fraction of a sunbathing session that is perceived by the individual to be a joint tanning-leisure activity. Pure sunbathing-session time is therefore given by $(1-\alpha) \theta$. In the extreme cases, $\alpha=0$ reflects complete dissociation between sunbathing and leisure, whereas $\alpha=1$ indicates full integration of the two activities.

Tan fades away after some time (irrespective of how it has been produced), hence the individual may wish to reproduce it. Let $B$ and $S$ denote, respectively, the number of indoor and outdoor tanning sessions taken by the individual during a given period of time. Let $E$ denote leisure which is not jointly consumed with sunbathing. Total time devoted to leisure activities, $L$, is thus given by

$$
L=\alpha \theta S+E .
$$

Assuming that the individual's working time is institutionally fixed, tan production competes with leisure on non-working time, $N$. The individual's time constraint is thus given by

$$
B+(1-\alpha) \theta S+L=N,
$$

where $(1-\alpha) \theta$ reflects the effective price of an outdoor tanning session in terms of forgone leisure. The individual faces a budget constraint as well, given by

$$
C+p B=I \text {, }
$$

where $C$ denotes spending on consumption of goods and services (other than tanning) and $I$ denotes fixed income.

Suppose that the individual does not enjoy the tanning process itself, but the final product only, which is a tanned look. The consumption of tanned look, $T$, is given by the number of times a new tan has been produced, which is the total number of sunbathing and booth tanning sessions taken over the period. That is,

$$
B+S=T .
$$

\footnotetext{
${ }^{4}$ While this seems to be the first attempt to address the tanning decision from an economic perspective, psychologists and sociologists have long been interested in the determinants of sunbathing and tanning salon use, applying theoretical non-economic decision-making models to explain these behaviors (e.g. [20] [21]).

${ }^{5}$ While the time it takes to get tanned indoor is determined by the type of skin and the (controlled) strength of ultraviolet radiation, the time it takes to get tanned in the sun depends on many factors such as latitude (ultraviolet rays are strongest in areas close to the equator), altitude (higher altitudes have greater ultraviolet exposure), season (the sun's angle in relation to the Earth is more direct during the summer months), time of the day (ultraviolet radiation is most intense at noon when the sun is at its highest point in the sky), reflection (some surfaces, such as snow, sand, grass, or water can reflect much of the ultraviolet radiation that reaches them) and weather conditions.
} 
Suppose further that the individual derives utility from the consumption of tanned look, leisure and other goods and services. For purpose of tractability, let the utility function be of the form

$$
V(C, T, L)=T L+U(C),
$$

where $U^{\prime}>0, U^{\prime \prime}<0$. That is, the utility function is assumed to be additively separable in $C$ and $T L$, increasing at decreasing marginal rates in the former but rising linearly in the latter. Being defined on the product $T L$, rather than separately on $T$ and $L$, it implies that a higher consumption of tanned look enhances at the margin the individual's enjoyment from leisure (and vice versa).

The individual may either be cancer-conscious (CC) or non-cancer-conscious (NCC). A CC individual is fully aware of the hazard of developing skin cancer associated with tanning and takes it into account when making her tanning decision. A NCC individual is either unaware of the hazard of skin cancer or ignores it when making her tanning decision. Let this hazard, $H$, be an increasing function of the number of indoor and outdoor tan sessions taken over the period. More specifically, suppose that a unit of time spent in booth tanning increases the hazard of skin cancer by $\lambda$ percentage points, whereas a unit of time spent sunbathing increases the hazard by $\pi$ percentage points. Hence

$$
H(B, S)=\lambda B+\pi \theta S .
$$

Since the ultraviolet radiation transmitted per unit of time through a tanning lamp is stronger than that transmitted by sunlight, we assume that $\lambda>\pi^{6}$. Nevertheless, because it takes more time to get tanned in the sun $(\theta>$ 1 ), the incremental hazard contributed by an outdoor tanning session, $\pi \theta$, may be greater than that contributed by an indoor session, $\lambda$.

Substituting now constraints (2)-(4) into the utility function (5), the NCC individual is assumed to choose $B^{*}$ and $S^{*}$ so as to maximize

$$
\psi(B, S)=(S+B)[N-B-(1-\alpha) \theta S]+U(I-p B) .
$$

For a CC individual, however, the hazard of skin cancer is a source of disutility that must be taken into account when determining her tanning intensity. The CC individual is thus assumed to choose $B^{*}$ and $S^{*}$ so as to maximize her net utility function, $V-H$. Combining (7) and (6), the net utility function, in terms of $B$ and $S$, is given by

$$
\varphi(B, S)=\psi(B, S)-(\lambda B+\pi \theta S)
$$

The first-order conditions for an interior solution to the maximization problem are:

$$
\begin{gathered}
\psi_{B}=N-2 B-[1+(1-\alpha) \theta] S-p U^{\prime}(I-p B)=0 \\
\psi_{S}=N-[1+(1-\alpha) \theta] B-2(1-\alpha) \theta S=0 .
\end{gathered}
$$

and

$$
\begin{aligned}
& \varphi_{B}=\psi_{B}-\lambda=0 . \\
& \varphi_{S}=\psi_{S}-\pi \theta=0 .
\end{aligned}
$$

for a NCC and CC individual, respectively ${ }^{7}$.

The solution to the first-order conditions yields the individual's demand for indoor and outdoor tanning sessions as a function of the parameters of the model. Of particular interest is the monetary price of indoor tanning,

\footnotetext{
${ }^{6}$ Woollons et al. [22] conducted an experiment which involved measuring the UV radiation emitted by tanning lamps as compared to the radiation emitted by the sun. The experiment was destined to examine mutagenic DNA damage, which is a prerequisite for the development of skin tumors, after exposure to artificial tanning lamps. During the experiment, human cells were exposed to two different commercial tanning beds containing 12 Philips 100W-R or 5 Philips TL80W/10R lamps. The UV radiation emitted by the tanning beds was measured at $85-100 \mathrm{~W} / \mathrm{m}^{2}$ and $35-40 \mathrm{~W} / \mathrm{m}^{2}$, respectively. The UV radiation emitted by the sun in full sunshine, with temperatures at about $25^{\circ} \mathrm{C}-34^{\circ} \mathrm{C}$, was found to be $10-28 \mathrm{~W} / \mathrm{m}^{2}$. The amount of UV radiation emitted by the tanning beds was thus $3-8$ times greater than that emitted by the sun.

${ }^{7}$ The second-order conditions for both the NCC and CC individuals are: $\psi_{B B}=-2+p^{2} U^{\prime \prime}<0 ; \psi_{S S}=-2(1-\alpha) \theta<0$;

$\psi_{B B} \psi_{S S}-\left(\psi_{B S}\right)^{2}>0$, where $\psi_{B S}=-[1+(1-\alpha) \theta]<0$. While the first two conditions are clearly satisfied, the third condition will be assumed to hold.
} 
which can be manipulated by public health policy makers through the imposition of a tan tax in order to affect the intensity of tanning and the consequent hazard of developing skin cancer.

\section{The Tan Tax and the Intensity of Tanning}

Consider first the effects of a $\tan \operatorname{tax}$ on the individual's choice of indoor and outdoor tanning intensities, $B^{*}$ and $S^{*}$.

Proposition 1: (a) A tan tax will reduce the number of indoor tanning sessions and increase the number of outdoor tanning sessions taken by the individual, irrespective of whether she is CC or NCC; (b) A tan tax will reduce the overall number of tanning sessions taken by the individual if she is NCC; however, if the individual is $C C$, a tan tax will reduce the overall number of tanning sessions only if $(1-\alpha) \theta>1$ but will increase it if $(1-\alpha) \theta<1$.

Proof: A tan tax on indoor tanning is bound to raise the price per session. Totally differentiating either the first-order conditions (8) and (9) or the first-order conditions $\left(8^{\prime}\right)$ and ( $\left(9^{\prime}\right)$ with respect to $B, S$, and $p$, we obtain

$$
\begin{aligned}
& \frac{\mathrm{d} B^{*}}{\mathrm{~d} p}=-\frac{U^{\prime}-p B U^{\prime \prime}}{\Delta}[2(1-\alpha) \theta]<0 \\
& \frac{\mathrm{d} S^{*}}{\mathrm{~d} p}=\frac{U^{\prime}-p B U^{\prime \prime}}{\Delta}[1+(1-\alpha) \theta]>0,
\end{aligned}
$$

where $\Delta \equiv \psi_{B B} \psi_{S S}-\left(\psi_{B S}\right)^{2}>0$ is a second-order condition for utility maximization (see footnote 7 ). It thus follows that $B^{*}$ is negatively related to $p$ and $S^{*}$ is positively related to it. This proves part (a) of Proposition 1 . To prove part (b), we totally differentiate (4), using (10) and (11), obtaining

$$
\frac{\mathrm{d} T}{\mathrm{~d} p}=\frac{U^{\prime}-p B U^{\prime \prime}}{\Delta}[1-(1-\alpha) \theta] \text {. }
$$

Hence, $T$ is negatively related to $p$ if $(1-\alpha) \theta>1$ but positively related to $p$ if $(1-\alpha) \theta<1$. Equating the first-order conditions (8) and (9) reveals that for a NCC individual the optimum solution must satisfy

$$
[1-(1-\alpha) \theta](S+B)=-p U^{\prime}(I-p B) \text {. }
$$

Because the right hand-side of Equation (13) is negative, it follows that an interior solution holds only if $(1-\alpha) \theta>1$. Hence, a tan tax is bound to reduce the overall number of tanning sessions taken by the NCC individual. However, equating the first-order conditions ( $\left.8^{\prime}\right)$ and $\left(9^{\prime}\right)$ reveals that the optimum solution of a CC individual satisfies

$$
[1-(1-\alpha) \theta](S+B)+\lambda-\pi \theta=-p U^{\prime}(I-p B),
$$

which may hold for both $(1-\alpha) \theta>1$ and $(1-\alpha) \theta<1$. Hence, a tan tax may either decrease or increase the overall number of tanning sessions taken by the $\mathrm{CC}$ individual, proving part (b) of Proposition 1. QED

The last result implies that for a CC individual a tan tax may increase outdoor tanning by more than is needed to compensate for the fall in indoor tanning. This could happen if a significant fraction of an outdoor session is perceived as leisure, so that the effective time cost of an outdoor session in terms of forgone leisure, $(1-\alpha) \theta$, is small and falls below the time cost of an indoor session, 1. It may seem odd that an interior solution would hold when the differential time cost of indoor tanning, $1-(1-\alpha) \theta$, is positive, because this implies that indoor tanning does not only involve a monetary cost, but is also more costly than outdoor tanning in terms of forgone leisure, hence a corner solution of $B^{*}=0$ is in place. Nevertheless, for a CC individual who takes into account the hazard of skin cancer when making her tanning decision, an interior solution is still possible if $(1-\alpha) \theta<1$, providing that an indoor tanning session is less risky than an outdoor session, or that the differential hazard of indoor tanning (as compared to outdoor tanning), $\lambda-\pi \theta$, is negative.

\section{The Tan Tax and the Hazard of Skin Cancer}

Consider now the effect of a tan tax on the hazard of skin cancer. Totally differentiating the hazard function (6) with respect to $p$, using Equation (4), yields 


$$
\frac{\mathrm{d} H}{\mathrm{~d} p}=\pi \theta \frac{\mathrm{d} T}{\mathrm{~d} p}+(\lambda-\pi \theta) \frac{\mathrm{d} B}{\mathrm{~d} p}
$$

While Proposition 1(a) establishes that the sign of $\mathrm{d} B / \mathrm{d} p$ is negative, the sign of (14) depends also on the signs of $\lambda-\pi \theta$ and $\mathrm{d} T / \mathrm{d} p$. By Proposition 1(b), the latter is determined by the sign of $1-(1-\alpha) \theta$, which is always negative for a NCC individual but may be positive for a CC individual. Table 1 summarizes the possible effects of the tan tax on the hazard of skin cancer for alternative signs of $\lambda-\pi \theta$ and $1-(1-\alpha) \theta$, distinguishing between $\mathrm{CC}$ and NCC individuals ${ }^{8}$.

As revealed by Table 1, a prerequisite for a tan tax to increase the hazard of skin cancer is that $\lambda-\pi \theta<0$; i.e., that the differential hazard of an indoor tanning session is negative. Given this prerequisite, a $\mathrm{CC}$ individual will end up increasing her risk of developing skin cancer if $(1-\alpha) \theta \leq 1$ (a condition that cannot hold at the interior optimum of a NCC individual). Still, both CC and NCC individuals might end up increasing the risk of cancer if $(1-\alpha) \theta>1$.

We now derive a general condition on the parameters of the model under which a tan tax will unambiguously increase the hazard of skin cancer for both a $\mathrm{CC}$ and a $\mathrm{NCC}$ individual.

Proposition 2: Let $\rho(\alpha, \theta) \equiv \frac{2(1-\alpha) \theta}{1+(1-\alpha) \theta}$. A tan tax will unambiguously increase the hazard of skin cancer for both CC and NCC individuals if $\rho(\alpha, \theta) \lambda<\pi \theta$.

Proof: Substituting (10) and (12) in (14) and rearranging, we obtain

$$
\frac{\mathrm{d} H}{\mathrm{~d} p}=\frac{U^{\prime}-P B U^{\prime \prime}}{\Delta}\{\pi \theta[1+(1-\alpha) \theta]-2(1-\alpha) \theta \lambda\}
$$

Hence, the sign of equation (15) will be positive if $\rho(\alpha, \theta) \lambda<\pi \theta$. QED

Notice that when $(1-\alpha) \theta \leq 1, \rho(\alpha, \theta) \leq 1$. In this case, $\lambda<\pi \theta$ is sufficient to ensure, as argued earlier, that the hazard of skin cancer for a $\mathrm{CC}$ individual increases with the imposition of the tan tax. In contrast, when $(1-\alpha) \theta>1, \rho(\alpha, \theta)>1$. Because in this case the overall number of tanning sessions, for both CC and NCC individuals, falls with the imposition of the tan tax, a stricter condition $\rho(\alpha, \theta) \lambda<\pi \theta$, is required for the hazard of skin cancer to increase.

Evidently, the extent by which sunbathing is perceived as sort of leisure rather than purely as an input in the tan production process plays a crucial role in determining the effect of the tan tax. It is easily seen that $\rho_{\alpha}(\alpha, \theta)<0$, hence the higher the level of $\alpha$, the lower is $\rho(\alpha, \theta)$. It thus follows that the greater the fraction of a sunbathing session perceived as leisure, the more likely is the tan tax to exacerbate the hazard of skin cancer.

While the hazard function has been assumed, for simplicity, to be linear in $B$ and $S$, Proposition 2 would also hold for more general functions. Consider alternatively the quadratic function $Z(B, S)=[H(B, S)]^{2}$. For a NCC individual, the results remain the same, because (a) she ignores the hazard function when making her tanning decision and (b) $\mathrm{d} Z / \mathrm{d} p=2 H(\mathrm{~d} H / \mathrm{d} p)$, hence $\operatorname{sign}(\mathrm{d} Z / \mathrm{d} p)=\operatorname{sign}(\mathrm{d} H / \mathrm{d} p)$. For a CC individual, how-

Table 1. The effect of a tan tax on the hazard of skin cancer.

\begin{tabular}{cccc}
$\lambda-\pi \theta>0$ & $\lambda-\pi \theta=0$ & $\lambda-\pi \theta<0$ & \\
irrelevant & irrelevant & CC: increases & $(1-\alpha) \theta<1$ \\
& & NCC: irrelevant & $(1-\alpha) \theta=1$ \\
irrelevant & irrelevant & CC: increases & $(1-\alpha) \theta>1$ \\
CC: decreases & CC: decreases & CC: irrelevant & NCC: ambiguous \\
NCC: decreases & NCC: decreases & NC) & \\
\hline
\end{tabular}

${ }^{8}$ Entries in Table 1 are marked "irrelevant" if the sign combination of $\lambda-\pi \theta$ and $1-(1-\alpha) \theta$ cannot hold in an interior solution; i.e. if it does not conform with Equations (13) and (13'). 
ever, the last terms of the first-order conditions ( $\left(8^{\prime}\right)$ and $\left(9^{\prime}\right)$ must be replaced with the terms $-H_{B}(=-2 \lambda \mu H)$ and $-H_{S}(=-2 \pi \theta H)$, respectively, which become dependent on $B$ and $S$. Differentiating the adjusted first-order conditions to determine the individual's response to a tax tan now involves second-order partial derivatives of the hazard function. Specifically, Equations (10) and (11) now include (within the square brackets) the terms $-H_{S S}\left(=-2 \pi^{2} \theta^{2}\right)$ and $H_{S B}(=2 \lambda \mu \pi \theta)$, respectively. It thus follows that Equation (12) must be adjusted to include the expression $H_{S B}-H_{S S}[=2 \pi \theta(\lambda \mu-\pi \theta)]$. Substituting, however, the adjusted Equations (10) and (12) into (14), which must now be multiplied by $2 H$, the hazard function derivatives fade out since $\pi \theta\left(H_{S B}-H_{S S}\right)-(\pi \theta-\lambda \mu)\left(-H_{S S}\right)=0$. It thus follows that Proposition 2 continues to hold.

\section{Concluding Remarks}

Applauding the recent imposition of a sales tax on indoor tanning, the AAD expects it to discourage the use of tanning booths and consequently to bring about a significant reduction in the hazard of skin cancer and the future costs of treating this disease. The present paper challenges this expectation on the ground that it overlooks tanners' option to compensate for their reduced frequency of visiting tanning salons by intensifying their exposure to the sun, an alternative which may embody a greater hazard. Developing a rational indoor-outdoor tanning choice model to examine both the cancer-conscious tanner's and the non-cancer-conscious tanner's reaction to the imposition of a tan tax, the paper identifies conditions on the parameters of the model under which a $\tan$ tax would rather exacerbate the hazard of skin cancer.

Clearly, a prerequisite for the tan tax to adversely affect the hazard of skin cancer is that sunbathing is a readily available alternative to indoor tanning. While this is evidently the case in the sun-flooded states of southern USA, it is rarely so in the northern states. The AAD's expectation is likely to be realized in the latter case, but the opposite may occur in the former. At present, the AAD is strongly opposing a recent legislation effort to repeal the tan tax. In view of this paper's results, the AAD may settle for the exemption of sun-blessed states from the tan tax, restricting its opposition to its abolishment in the sun-deficient states.

The model developed in this paper may be extended in several ways to include some unaccounted for aspects of tan production, although at the cost of considerable mathematical complexity. First, the tanning process itself, not just the final product, may be a source of enjoyment to the tanner. There is some literature and anecdotal evidence suggesting that many tanners also enjoy the feelings of relaxation and warmth arising during the tanning process and may even develop an addiction to tanning. Other tanners, although enjoying their tanned look, may find tanning uncomfortable and even suffer throughout the process. Second, the decision to tan may be influenced by the behavior of others, thus a social norm of tanning may be incorporated into the model. With many peers putting on the tanned look, one will be more likely to engage in its production. Third, tanners may self-protect against the risk of cancer by using sunscreen when exposed to the sun. An extended model can allow the individual to determine not just the time devoted to indoor tanning and sunbathing, but also the fraction of time to use sunscreen when sunbathing. While prolonging the time it takes to get tanned, it reduces the risk involved. All these features would interfere with the simplicity of the present model, but by enabling consideration of a wider range of behaviors, they may allow some additional conclusions to be drawn.

\section{References}

[1] Fisher, G.J., Wang, Z.Q., Datta, S.C., Varani, J., Kang, S. and Voorhees, J.J. (1997) Photophysiology of Premature Skin Aging Induced by Ultraviolet Light. The New England Journal of Medicine, 337, 1419-1429. http://dx.doi.org/10.1056/NEJM199711133372003

[2] National Cancer Institute (2010) What You Need to Know about ${ }^{\mathrm{TM}}$ Melanoma and Other Skin Cancers. http://www.cancer.gov/publications/patient-education/wyntk-skin-cancer

[3] Heckman, C.J., Coups, E.J. and Manne, S.L. (2008) Prevalence and Correlates of Indoor Tanning among USA Adults. Journal of the American Academy of Dermatology, 58, 769-780. http://dx.doi.org/10.1016/j.jaad.2008.01.020

[4] Lazovich, D.A., Isaksson Vogel, R., Berwick, M., Weinstock, M.A., Anderson, K.E. and Warshaw, E.M. (2010) Indoor Tanning and Risk of Melanoma: A Case-Control Study in a Highly Exposed Population. Cancer Epidemiology, Biomarkers and Prevention, 19, 1557-1568. http://dx.doi.org/10.1158/1055-9965.EPI-09-1249

[5] Lim, H.W., Gilchrest, B.A., Cooper, K.D., Bischoff-Ferrari, H.A., Rigel, D.S., Cyr, W.H., Miller, S., DeLeo, V.A., Lee, 
T.K., Demko, C.A., Weinstock, M.A., Young, A., Edwards, L.S., Johnson, T.M. and Stone, S.P. (2005) Sunlight, Tanning Booths, and Vitamin D. Journal of the American Academy of Dermatology, 52, 868-876.

http://dx.doi.org/10.1016/j.jaad.2005.03.015

[6] Poorsattar, S.P. and Hornung, R.L. (2007) UV Light Abuse and High-Risk Tanning Behavior among Undergraduate College Students. Journal of the American Academy of Dermatology, 56, 375-379. http://dx.doi.org/10.1016/i.jaad.2006.08.064

[7] Stryker, J.E., Yaroch, A.L., Moser, R.P., Atienza, A. and Glanz, K. (2007) Prevalence of Sunless Tanning Product Use and Related Behaviors among Adults in the United States: Results from a National Survey. Journal of the American Academy of Dermatology, 56, 387-390. http://dx.doi.org/10.1016/j.jaad.2006.08.051

[8] Hoerster, K.D., Garrow, R.L., Mayer, J.A., Clapp, E.J., Weeks, J.R., Woodruff, S.L., Sallis, J.F., Slymen, D.J., Patel, M.R. and Sybert, S.A. (2009) Density of Indoor Tanning Facilities in 116 Large USA Cities. American Journal of Preventive Medicine, 36, 243-246. http://dx.doi.org/10.1016/j.amepre.2008.10.020

[9] World Health Organization (2003) Artificial Tanning Sunbeds: Risks and Guidance. http://www.who.int/uv/publications/en/sunbeds.pdf

[10] American Academy of Dermatology (2011) Indoor Tanning Tax Sends Strong Health Message: Indoor Tanning Is Unsafe.

http://www.prnewswire.com/news-releases/indoor-tanning-tax-sends-strong-health-message-indoor-tanning-is-unsafe124776368.html

[11] CNN Money (2010) Tanning Salons Burned by Health Care Bill. http://money.cnn.com/2010/03/24/news/economy/tanning_tax/

[12] Sayre, R.M. and Dowdy, J.C. (2003) Sunbathing vs. Indoor Tanning: A Realistic Perspective. Photodermatology, Photoimmunology and Photomedicine, 19, 105-107. http://dx.doi.org/10.1034/j.1600-0781.2003.00028.x

[13] Peltzman, S. (1975) The Effects of Automobile Safety Regulation. Journal of Political Economy, 83, 677-726. http://dx.doi.org/10.1086/260352

[14] Evans, W.N. and Farrelly, M.C. (1998) The Compensating Behavior of Smokers: Taxes, Tar, and Nicotine. RAND Journal of Economics, 29, 578-595. http://dx.doi.org/10.2307/2556105

[15] Green, C.G. (2003) Rethinking AIDS Prevention: Learning from Successes in Developing Countries. Praeger Publishers, Westport.

[16] Yaniv, G., Rosin, O. and Tobol, Y. (2009) Junk Food, Home Cooking, Physical Activity and Obesity: The Effect of the Fat Tax and the Thin Subsidy. Journal of Public Economics, 93, 823-830. http://dx.doi.org/10.1016/j.jpubeco.2009.02.004

[17] Fletcher, J.M., Frisvold, D.E. and Tefft, N. (2010) The Effects of Soft Drink Taxes on Child and Adolescent Consumption and Weight Outcomes. Journal of Public Economics, 94, 967-974. http://dx.doi.org/10.1016/j.jpubeco.2010.09.005

[18] Just, D.R. and Wansink, B. (2011) The Flat-Rate Pricing Paradox: Conflicting Effects of "All-You-Can-Eat" Buffet Pricing. Review of Economics and Statistics, 93, 193-200. http://dx.doi.org/10.1162/REST a 00057

[19] Siniver, E. and Yaniv, G. (2012) All-You-Can-Eat Buffet: Entry Price, the Fat Tax and Meal Cessation. The B.E. Journal of Economic Analysis and Policy, 12, 1-21.

[20] Hillhouse, J.J., Adler, C.M., Drinnon, J. and Turrisi, R. (1997) Application of Azjen's Theory of Planned Behavior to Predict Sunbathing, Tanning Salon Use, and Sunscreen Use Intentions and Behaviors. Journal of Behavioral Medicine, 20, 363-378. http://dx.doi.org/10.1023/A:1025517130513

[21] Turrisi, R., Hillhouse, J.J. and Gebert, C. (1998) Examination of Cognitive Variables Relevant to Sunbathing. Journal of Behavioral Medicine, 21, 300-313. http://dx.doi.org/10.1023/A:1018773101658

[22] Woollons, A., Clingen, P.H., Price, M.L., Arlett, C.F. and Green, M.H.L. (1997) Induction of Mutagenic DNA Damage in Human Fibroblasts after Exposure to Artificial Tanning Lamps. British Journal of Dermatology, 137, 687-692. http://dx.doi.org/10.1111/j.1365-2133.1997.tb01102.x 
Scientific Research Publishing (SCIRP) is one of the largest Open Access journal publishers. It is currently publishing more than 200 open access, online, peer-reviewed journals covering a wide range of academic disciplines. SCIRP serves the worldwide academic communities and contributes to the progress and application of science with its publication.

Other selected journals from SCIRP are listed as below. Submit your manuscript to us via either submit@scirp.org or Online Submission Portal.
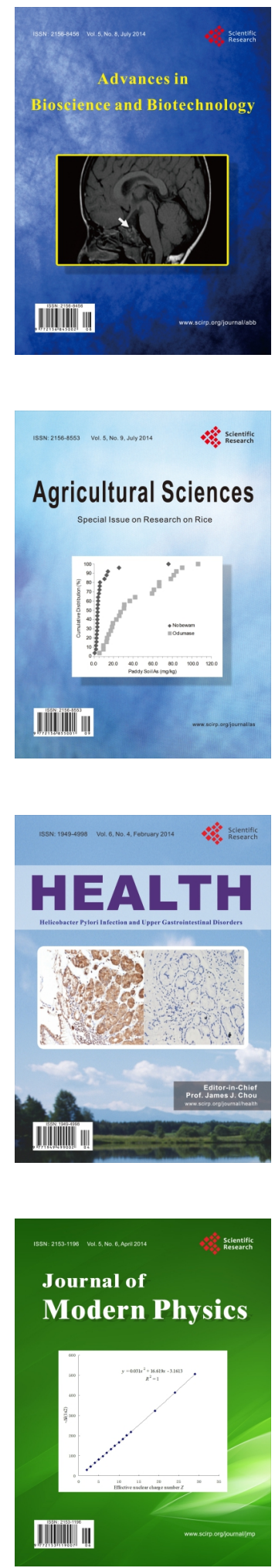
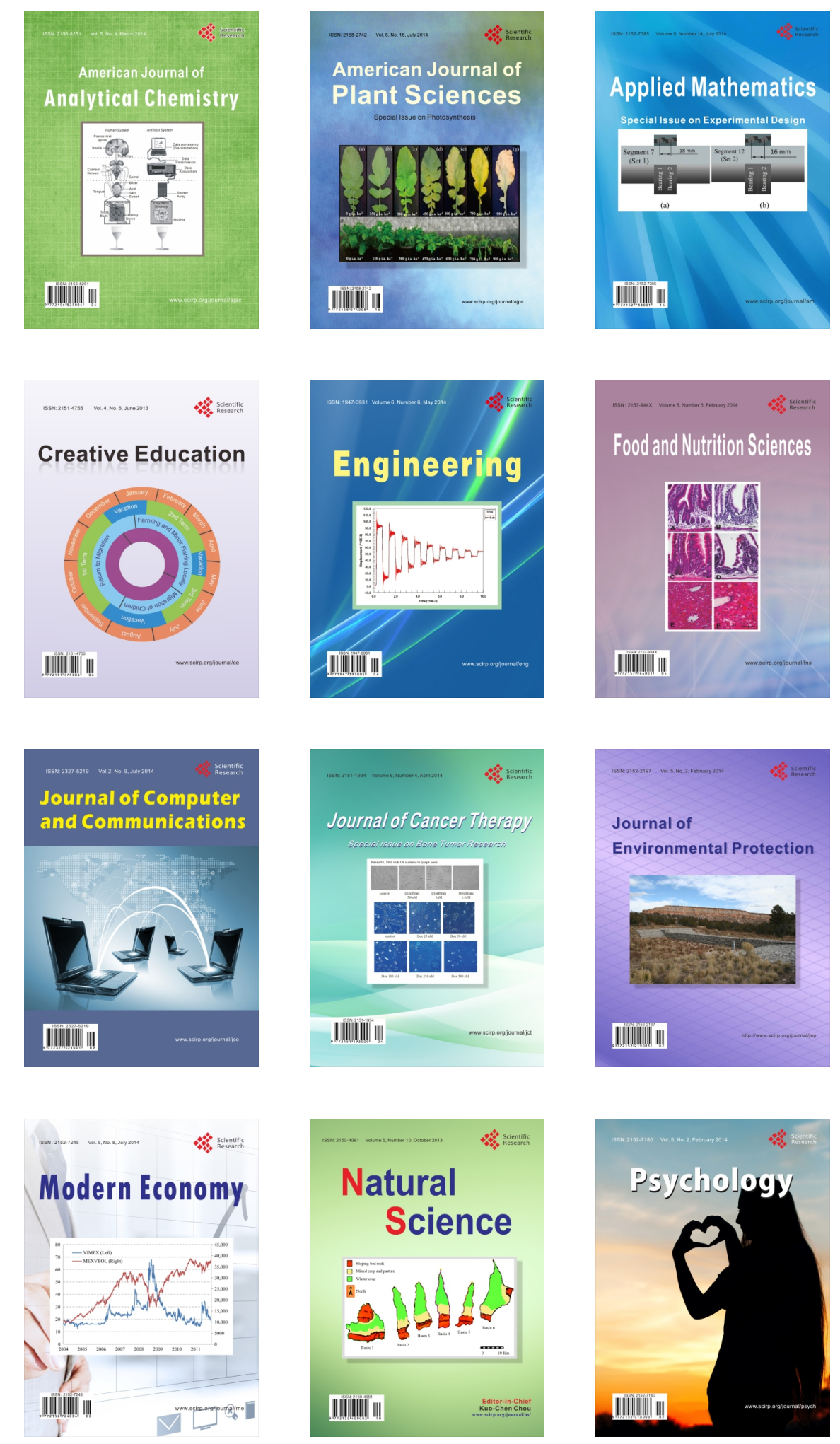